\title{
Strategy of complete preservation of the subvalvular structures in the mitral valve replacement
}

Dinara B. Toktosunova

Scientific Research Institute of Heart Surgery and Organ Transplantation, Bishkek, Kyrgyzstan

\begin{abstract}
Complete preservation of leaflets for mitral valve replacement to maintain geometry and the function of left ventricle in the near and distant period is necessary. The aim of study was to analyze these procedures.

Bileaflet preservation of the anatomical architectonics of the left ventricle in combination with the surgical reduction of the enlarged left atrium will allow to optimize the postoperative geometry and to improve the remodeling of all the left heart along with improved long-term results of patients with mitral valve replacement.
\end{abstract}

Key words: mitral valve replacement, preservation of leaflets, subvalvular apparatus

(Heart, Vessels and Transplantation 2019; 3: doi: 10.24969/hvt.2019.123)

Certainly, the most perspective direction in surgery of mitral valve (MV) is valve repair and preservation of subvalvular structures. However, in clinical practice there remain large group of patients that need mitral valve replacement (MVR) (1-3).

In this group of patients, the most important is to save the function of left ventricle (LV) in the short and longterm period. One of the basic conditions, which determine an adequate LV contractility, is correct geometrical cavity shape. This causes the optimal intracardiac flow directions, myocardium contractility and heart rhythm. (4-7).

Modern constructive estimation of the MV and it surgical anatomy shows that the atrioventricular valve (AV) represents more than just the valve which opens and closes in response to pressure changes. The structural anatomic interrelation of heart valves and the dynamic mechanisms involved in their function are fundamental for optimization of the valve function.

To date, it has been proven that the destruction of structural AV connections interrupts the forces separation during contraction and relaxation of the LV muscles. After destruction of those relationships between the papillary muscles and the heart base, LV gradually takes spherical shape and becomes less effective. Therefore, as a result heart failure occurs earlier and is associated with high mortality. Thus, there is no doubt that the destruction of annulopapillary contact seriously violates the perfectly organized operation of the heart.

In 1964, Lillehei first reported about inconsistent longterm results of MVR while the entire native valve and its ventricular components were removed. Despite the satisfactory function of prosthetic valves, approximately $50 \%$ of patients have died of heart failure during 5 years. Autopsy of the hearts revealed a spherical modification of the shape of the ventricular cavity (8). However, at that time, this concept was not developed. The complication of the operation's technique, delay of ischemia's period, the risk of spherical prosthesis dysfunction and the potential necessity for implantation of smaller size prosthesis were thought to be the main factors, contributing to mortality.

To this hypothesis returned after Millers et al., publication in 1979, when the authors reported about decrease in mortality due to the low risk of LV posterior wall rupture. There was no mortality and prosthesis dysfunction in patients with MV posterior cusp and subvalvular structures preservation (9).

Address for Correspondence: Dinara B. Toktosunova, Scientific Research Institute of Heart Surgery and Organ Transplantation, Bishkek, Kyrgyzstan, Email: dinara.toktosunova@mail.ru

Received: 25.01.2019 Revised: 11.04.2019 Accepted: 15.04.2019 CopyrightC2019 Heart, Vessels and Transplantation 
David et al., in 1981, assessed the importance of preserving the chordal-papillary apparatus in LV function after animal's MVR and received improvement of LV function in the preservation of subvalvular apparatus group (10). Similar results were also obtained in experimental animal studies. It was demonstrated that the intersection of dog heart chords led to increase of the long LV axis, causes reduction in contractility, which can only be supported by higher preload and increased myocardial contractility (11).

Hetzer et al., confirmed these data in 1983 and 1995. They demonstrated improvement in LV function while preserving chords of the posterior cusp and concluded that saving of all subvalvular structures is possible in almost all cases $(12,13)$.

In 1987, on dogs' hearts Hansen demonstrated that the intersection of the chord of the anterior leaflet $M V$ reduced $L V$ function more than the intersection of the chords from the posterior leaflet. He suggested that since the anterior leaflet was larger than the posterior leaflet the development of tension in the chords of that cusp should be greater at a given LV pressure (14).

Subsequently, many reports showing the validity, efficiency and safety of preservation of the subvalvular structures during MVR appeared. Furthermore, in the last decade, publications have become available that indicate improved long-term results and survival while preserving subvalvular structures during MVR.

However, there are conflicting data in some publications. In the study by Coutinho et al., in 2015, a retrospective analysis of 605 patients who withstand valve replacement for rheumatic disease was conducted. The chord preservation from the posterior leaflet was performed in 224 (37.7\%) patients. The observation included 4259 patient-years (range: 0-22 years), the average observation period $7.0 \pm 5.3$ years (average 5.2 years, range: 2.9-9.6 years), and was completed for $97 \%$ of patients. The authors considered that the reasons why surgeons did not preserve subvalvular structures were: gross calcifications and fibrosis of the valves and subvalvular structures, pronounced hypertrophy and small size of the LV and the probability of implantation of a smaller valve. In conclusion, the authors could not demonstrate the advantages of preserving the chords of the posterior leaflet in relation to the duration of survival (15).
In the 2014 by Lafci et al., reported results of a prospective study of 115 patients after MVR for rheumatic stenosis (in 48 cases the chords of the posterior cusp were preserved). During 18-month follow-up, all echocardiographic variables showed consistent improvement in the chord preserved group; mean LV ejection fraction worsened in the group without preservation. During observation, diameter of the LV at the end of diastolic and systolic phases decreased. Also, LV ejection fraction was significantly higher in the group with preservation of the MV posterior cusp compared with the complete excision of subvalvular structures group (16).

In the study by Chowdhury et al. with larger number of patients included $(n=451)$, the effect of preserving the subvalvular structures in patients with rheumatic MV disease was specifically evaluated. The authors compared three groups (without preserving chords, preserving only chords of the posterior leaflet and preserving all structures), and found that groups with preserved chords showed significant improvement in LV function in short-term and long-term period after surgery (after 48 months). These authors also found that complete preservation was related to larger improvement in the final systolic volume of the LV in comparison with group without preservation. They concluded that the total chordal preservation is possible in most cases of rheumatic patients and provides significant long-term advantage by preserving LV function (17).

Various methods for chord conservation have been developed and proposed. Most of the methods describe the preservation of posterior cusp chords. Despite the anatomical and physiological validity, the preservation of the subvalvular structures of both valves still does not attract sufficient attention among cardiac surgeons. Currently, most heart surgeons prefer to maintain only one posterior leaflet. It is states that the preservation of chords only from the posterior cusp is enough. As the reason for this, some researchers indicate such disadvantages as technical difficulties in preserving the subvalvular apparatus of both valves that prolongs the operation, the possibility of implanting a smaller prosthesis and the possibility of disrupting the outflow pathways from the LV and the contact between the prosthesis and subvalvular structures $(18,19)$. 
In recent reports and clinical studies, there were data that prove the effectiveness and feasibility of fully preserving the subvalvular structures when replacing the MV (20). The literature describes a variety of strategies that can allow MVR without interfering with the function of subvalvular structures and LV contractility $(21,22)$.

In García-Fuster et al. publication, there were analyzed 566 patients who underwent valve replacement for rheumatic disease. Patients were divided into groups without preservation (n-156), with preservation of only the posterior leaflet $(n-248)$ and complete preservation ( $n-162)$. The actuarial survival curve (130 months) was better in group 3: $77.18 \%$, $85.38 \%$ and $93.22 \%$, respectively ( $p<0.01$ group 1 compared with group 3). Group 1 showed a lower cardiac index $(p<0.01)$ and more patients with heart failure NYHA class III and IV: $17.8 \%$ versus $3.9 \%$ and $2.0 \%(p<0.001)(23)$.

Timala et al. retrospectively analyzed the results of MVR of 93 patients. The observation has been more than 3 years. By the end of 3rd year of follow-up, patients without preservation and retaining only the posterior leaflet tended to increase LV end-diastolic dimension, while patients with complete preservation ( $n-53,56.99 \%$ ) tended to decrease LV end-diastolic dimension and good contractile function of both LV and right ventricle. The authors concluded that the complete preservation of the subvalvular apparatus during MVR allows obtaining the best effect on the contractile function and size of the LV in the long-term period (24).

Despite the fact that the effectiveness of preserving the subvalvular apparatus during MVR with degenerative changes of valves was proven, its applicability and possible benefits in rheumatic valves remain controversial $(15,17,25)$.

Chen L. et al., in their study shows that complete mitral leaflet preservation at the native anatomical position during MVR is feasible in rheumatic patients with an enlarged LV chamber and has significant advantages by preserving LV function and geometry. It is a safe and effective surgical technique (25).

This literature review showed the existing evidence for the advantages of complete preservation of subvalvular structures in valve replacement in the concept of improving immediate results and reducing the risk of dilated cardiomyopathy in the long-term period. According to the actuarial survival curve and the risk of developing heart failure, MVR with complete preservation of the subvalvular structures is not inferior to the results obtained with valve repair $(18,19)$. Even so, the methods of complete preservation of subvalvular structures are still not routinely used and are not included in clinical guidelines. Most researchers analyzing the results of MVR with or without preservation studied only linear echocardiographic parameters, and the LV and left atrium remodeling indices were not taken into account and were not studied.

\section{Conclusion}

Complete preservation of the anatomical architectonics of the LV in combination with the surgical reduction of enlarged left atrium will allow postoperative geometry optimization and improve left heart remodeling with improved long-term results in patients with MVR. Better left heart remodeling after MVR with complete preservation of the subvalvular structures allows more extensive use of these surgical techniques, especially in patients with dilatation of the LV cavity or reduced functional reserves of the LV myocardium.

Peer-review: Internal and external Conflict of interest: None to declare

Authorship: D.T. Acknowledgement and funding: None to declare 


\section{References}

1. Mvondo CM, Pugliese M, Giamberti A, Chelo D, Kuate LM, Bombhi J, et al. Surgery for rheumatic mitral valve disease in sub-Saharan African countries: why valve repair is still the best surgical option. Pan Afr Med J 2016; 24: 307.

2. Grossi EA, Galloway AC, Miller JS, Ribakove GH, Culliford AT, Esposito $R$, et al. Valve repair versus replacement for mitral insufficiency: when is a mechanical valve still indicated? J Thorac Cardiovasc Surg 1998; 115: 389-94.

3. Zilla P, Koshy J, Brink J, Human P. Mitral valve replacement for rheumatic heart disease in Southern Africa. J Cardiothorac Surg. 2013; 8(Suppl 1): 0294.

4. Bockeria LA, Skopin II, Muratov RM. Echocardiographic assessment of cardiac cavity remodeling in mitral valve insufficiency before and after replacement in the early postoperative period Ann Surg 2007; 1: 20-5.

5. Bonchek LI, Olinger GN, Siegel R, Tresch DD, Keelan $\mathrm{MH} \mathrm{Jr}$. Left ventricular performance after mitral reconstruction for mitral regurgitation. I Thorac Cardiovasc Surg 1984; 88: 122-7.

6. Feindel C, Tufail Z, David T, Ivanov J, Armstrong S. Mitral valve surgery in patients with extensive calcification of the mitral annulus. J Thorac Cardiovasc Surg 2003; 126: 777-81.

7. Hansen DE, Sarris GE, Niczyporuk MA, et al. Physiologic role of the mitral apparatus in left ventricular regional mechanics, contraction synergy and global left ventricular systolic function. J Thorac Cardiovasc Surg 1989; 97:521.

8. Lillehei CW, Levy MJ, Bonnabeau RC. Mitral valve replacement with preservation of papillary muscles and chordae tendineae. J Thorac Cardiovasc Surg 1964; 47: 532.

9. Miller DW Jr, Johnson DD, Ivey TD. Does preservation of the posterior chordae tendineae enhance survival during mitral valve replacement?, Ann Thorac Surg 1979; 28: 22-7.

10. David TE, Strauss HD, Mesher E, Anderson MJ, MacDonald IL, Buda AJ. Is it important to preserve the chordae tendineae and papillary muscles during mitral valve replacement?, Can J Surg 1983; 24: 236-9.

11. Gams E, Hagl S, Schad H, Heimisch W, Mendler N, Sebening F. Significance of the subvalvular apparatus for left ventricular dimensions and systolic function: experimental replacement of the mitral valve. Thorac Cardiovasc Surg 1991; 39: 5-12.

12. Hetzer R, Bougioukas G, Franz M, Borst HG. Mitral valve replacement with preservation of the papillary muscles and chordae tendineae-revival of a seemingly forgotten concept. I. Preliminary clinical report, Thorac Cardiovasc Surg 1983; 31: 291-6.

13. Hetzer $R$, Drews $T$, Siniawski $H$, Komoda $T$, Hofmeister J, Weng Y. Preservation of papillary muscles and chordae during mitral valve replacement: possibilities and limitations, J Heart Valve Dis 1995; 4 Suppl. II; S115-S123.

14. Hansen DE, Cahill PD, Derby GC, Miller DC. Relative contributions of the anterior and posterior mitral chordae tendineae to canine global left ventricular function. J Thorac Cardiovasc Surg 1987; 93: 45-55.

15. Coutinho GF, Bihun V, Correia PE, Antunes PE, Antunes MJ. Preservation of the subvalvular apparatus during mitral valve replacement of rheumatic valves does not affect long-term survival. Eur J Cardiothorac Surg 2015; 48: 861-7.

16. Lafci G, Cagli K, Cicek OF, Korkmaz K, Turak O, Uzun $A$, et al. Papillary muscle repositioning as a subvalvular apparatus preservation technique in mitral stenosis patients with normal left ventricular systolic function. Tex Heart Inst J 2014; 41: 33-9.

17. Chowdhury UK, Kumar AS, Airan B, Mittal D, Subramaniam G, Prakash $R$, et al. Mitral valve replacement with and without chordal preservation in a rheumatic population: serial echocardiographic assessment of LV size and function. Ann Thorac Surg $2005 ; 79: 1926-33$.

18. Tanaka H, Yamshita T, Okada K, Nakagiri K, Kawanishi Y, Okita Y, et al. Feasibility of preservation of subvalvular apparatus in mitral valve replacement with the On-X mechanical valve J Thorac Cardiovasc Surg 2006;132:1470-1.

19. Kisamori E, Otani S, Yamamoto T, Nishiki M, Yamada $Y$, Matsumoto $T$. Mitral valve repair versus replacement with preservation of the entire subvalvular apparatus. Gen Thorac Cardiovasc Surg. 2018 Nov 23. doi: 10.1007/s11748-018-1039-2.

20. Sintek CF, Pfeffer TA, Kochamba GS, Khonsari S. Mitral valve replacement: technique to preserve the subvalvular apparatus. Ann Thorac Surg 1995; 59: 1027-9. 
21. Alsaddique AA. Mitral valve replacement with the preservation of the entire valve apparatus. Rev Bras Cir Cardiovasc 2007; 22: 218-23.

22. Kuralay E, Demirkilic U, Gunay C, Tatar H. Mitral valve replacement with bileaflet preservation: a modified technique. Eur J Cardio-Thorac Surg 2002; 22: 630-2.

23. García-Fuster R, Estevez V, Gil O, Cánovas S, Martínez-Leon J. Mitral valve replacement in rheumatic patients: effects of chordal preservation. Ann Thorac Surg 2008; 86: 472-81;
24. Timala RB, Joshi D, Aryal M, Bhandari K, Singh $Y$, Sharma J. Effects of subvalvular apparatus preservation in mitral valve replacement among rheumatic patients: early and mid term follow up. Journal of Institute of Medicine 2016; 38: 2-3.

25. Chen L, Chen B, Hao J, Wang X, Ma R, Cheng W, et al. Complete preservation of the mitral valve apparatus during mitral valve replacement for rheumatic mitral regurgitation in patients with an enlarged left ventricular chamber. Heart Surg Forum 2013; 16: E137-43. 